\title{
Numerical Simulation of Steel-Laminated Bearing Considering Friction Slipping
}

\author{
Weiguo Huang, Xiuli Xu, Kairui Wang, and Weiqing Liu
}

\begin{abstract}
In order to obtain a more precise seismic response of steel-laminated elastomeric bearing, which is widely used in middle-span bridges, a three-dimensional finite element model of this bearing is built by ABAQUS software, incorporating material, geometric nonlinearities, and frictional contact between bearing surfaces and plates. Analytical simulation is carried out to study the behavior of steel-laminated elastomeric bearing under the compression and shear, adapting both penalty friction model and static-kinetic exponential decay friction model. The results about hysteretic curve and equivalent viscous damping ratio are compared with test one. The results show that the numerical results using static-kinetic exponential decay friction model are in good accordance with the test one, so the numerical model can simulate the behavior of experimental bearings well and is accurate enough to simulate the bearing friction slipping. Further parameter analysis on the influence of pressure and velocity of slipping is conducted, for bridge seismic design and analysis.
\end{abstract}

Index Terms-Steel-laminated elastomeric bearing, Analytical simulation, penalty friction model, static-kinetic exponential decay friction model.

\section{INTRODUCTION}

Steel-laminated elastomeric bearings (SLEB) are widely used in small-span and medium span bridges for its low cost and convenience in engineering practice, which is an important kind of component to connect the superstructure (main girder) and substructure (piers). SLEB transfers the inertia force of the girder to the pier under earthquake. Studies shows that sliding of bearings can reduce the inertia force of the girder, can play a certain isolation effect, and can make use of this sliding bearing friction properties in seismic design.

At present, the study on the performance of SLEB mainly base on the FEM analysis, due to the material and geometric nonlinearities of rubber, and frictional contact [1]-[4]. But few studies has been done considering the friction coefficient changing by pressure and relative speed between the contact surfaces of bearing and plates[5], [6]. Some experiments are also carried out to study the slipping performance of SLEB [7], [8]. Theoretical analysis also has been carried out based on elasticity [9]. So it is necessary to study the characteristics of SLEB considering both friction slipping and material

Manuscript received Janurary 24, 2017; revised June 1, 2017. This work was supported in part by the National Natural Science Foundation of China (Grant No.51178220 and 51108234), the Transportation Science and Technology project (2013Y12), and the Science and technology support program (BE2014716), Jiangsu, China.

The authors are with Nanjing Tech University, Nanjing, China (e-mail: colinering@126.com, kairuiking@sina.com, njxuxiuli@163.com, wqliu@njtech.edu.cn). nonlinearities.

To study the characteristics of bearing friction slipping effects, we use ABAQUS software and build a three-dimensional finite element model for parameter analysis, on the basis of the bearing test. Penalty friction model and static-kinetic exponential decay friction (SEDF) model are adopted respectively to simulate the friction sliding behavior of SLEB under the load of compression-shearing. The simulation results show good accordance with the test results, which can be used as a guidance in bridge structure seismic design and analysis.

\section{Constitutive Model of Materials}

SLEB consists of rubber layers and steel shims. Finite element analysis is carried out using ABAQUS software. Rubber and steel use hyperelastic model and elastic model respectively.

\section{A. Rubber Constitutive Model}

On a macroscopic level, the behavior of the rubber exhibits certain characteristics: (1) it can undergo large elastic deformation; (2) there is little volume change when stress is applied. For rubber, a hyperelastic material, the energy density function model is widely used to define its constitutive model, instead of by the parameters Young's modulus and Poisson ratio.

The energy density function model of hyperelastic materials is defined as follows:

$$
U=\sum_{i+j=1}^{N} C_{i j}\left(I_{1}-3\right)^{i}\left(I_{2}-3\right)^{j}+\sum_{k=1}^{N}(J-1)^{2 k} / D_{1}
$$

where $\mathrm{N}$ is the order of polynomial function; $C_{i j}, D_{1}$ are undetermined parameters, $J$ is the elastic volume ratio. For incompressible material, $J=1$, the formula can be reduced to:

$$
U=C_{10}\left(I_{1}-3\right)+\mathrm{C}_{01}\left(I_{2}-3\right)
$$

\section{B. Parameters of Constitutive Models}

In order to obtain the parameters of rubber materials, uniaxial tensile test rubber specimen is carried out. The length of specimen is $25 \mathrm{~mm}$, the cross section is $2 \mathrm{~mm} \times 6 \mathrm{~mm}$. The specimen is shown in Fig. 1. In this paper, the Mooney-Rivlin material model [10] is adapted, the material model can well describe the mechanical properties of rubber materials. According to the rubber material test to determine the parameters, $\mathrm{C} 10=0.37 \mathrm{MPa}, \mathrm{C} 01=0.03 \mathrm{MPa}$. The rubber 
material stress-strain curve test data compared with FEM results is shown in Fig. 2.

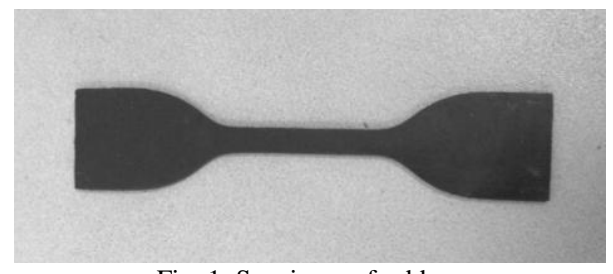

Fig. 1. Specimen of rubber.

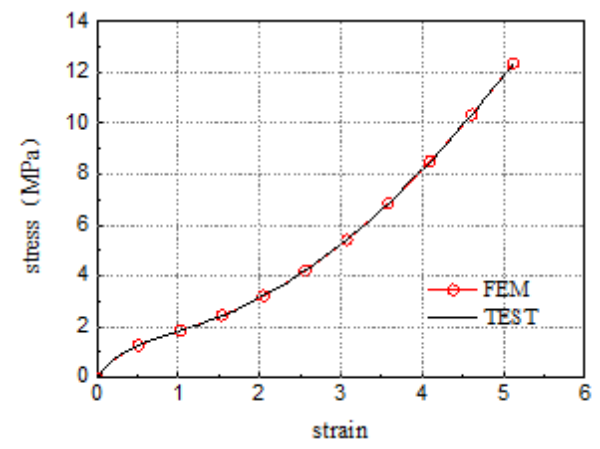

Fig. 2. Stress-strain curves of rubber under tensile load.

\section{NUMERICAL ANALYSIS}

A three-dimensional finite element model of SLEB was established, considering the hyperelastic properties of rubber materials and the complex interaction between plate and the surface of the rubber bearing. Test bearing profile is shown in Fig. 3.

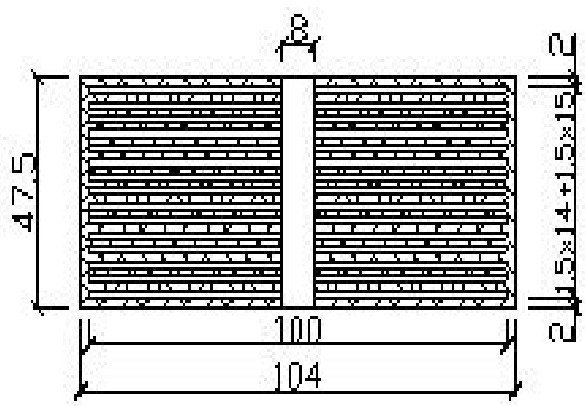

Fig. 3. Profile of SLEB (unit: $\mathrm{mm}$ )

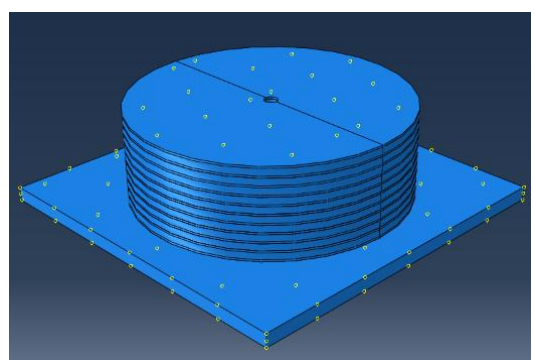

Fig. 4. Contact areas of SLEB and plate.

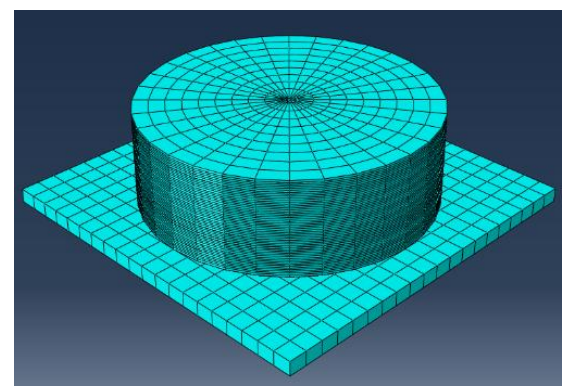

Fig. 5. Mesh generation of FEM model.

\section{A. Finite Element Type and Meshing}

For rubber material is a kind of incompressible hyperelastic materials, ordinary element in FEM may cause numerical problems, such as shear locking and convergence problem. Therefore in this paper, rubber layers are modeled by 8 -node hybrid element $(\mathrm{C} 3 \mathrm{D} 8 \mathrm{H})$, and steel shims are modeled by 8-nodes reduction element (C3D8R). Steel is treated as a linear elastic material. Its elastic modulus is $200 \mathrm{GPA}$, and Poisson's ratio is 0.3 . Steel shims and rubber layers are bound together. There are 15 rubber layers and 14 steel shims in one SLEB. SLEB and plate consist of the whole model (Fig. 4). The mesh generation is shown in Fig. 5.

\section{B. Friction Models}

In ABAQUS, the frictional contact between SLEB and plates is defined by normal and tangential behavior. Normal behavior is defined by hard contact, which means that the pressure between the contact surfaces is not restricted, and when the pressure decrease to zero or less, the two contact surfaces will separate. The tangential behavior is defined as follows:

$$
\tau_{c}=\min \left(\mu P, \tau_{\max }\right)
$$

where $\tau_{c}$ is the critical shearing stress; $\mu$ is the friction coefficient; $P$ is the normal pressure; $\tau_{\max }$ is the max friction stress limit.

Penalty friction (coulomb friction) model and SEDF model are used to simulate the tangential contact behavior. In penalty friction model, friction coefficient is a constant, which will not change by the contact pressure or velocity, and is a discontinuous model. In SEDF model, friction coefficient is a not a constant, which will change by the contact velocity, which is more reasonable and can perform a good simulation of SLEB sliding from sticking to slipping. The friction coefficient in SEDF model is defined as follows:

$$
\mu=\mu_{k}+\left(\mu_{s}-\mu_{k}\right) \mathrm{e}^{-d_{c} v}
$$

where $\mu_{k}$ is the dynamic friction coefficient, $\mu_{s}$ is the static friction coefficient, $d_{c}$ is the decay ratio; $v$ is the slipping ratio.

\section{VERIFICATION OF SHEARING STIFFNESS OF SLEB}

In compression-shearing test, the vertical load weight is 1.0 $\mathrm{t}$, and horizontal loading speed is $0.5 \mathrm{~mm} / \mathrm{s}$, at an amplitude of $25 \mathrm{~mm}$. Experimental results compared with the FEM one are shown in Fig. 6. The shear stiffness of bearing is calculated FEM results, and the average value of shear stiffness is 250.0 $\mathrm{N} / \mathrm{mm}$, which is very close to the theoretical value 249.6 $\mathrm{N} / \mathrm{mm}$ and experimental value $241.0 \mathrm{~N} / \mathrm{mm}$, and proves that the FEM simulation is accurate. The shearing stiffness of SLEB in FEM model is given in Table I.

TABLE I: SHEARING STIFFNESS OF SLEB IN FEM MODEL

\begin{tabular}{ccc}
\hline \hline Shearing force $(\mathrm{kN})$ & Deformation $(\mathrm{mm})$ & Shearing stiffness $(\mathrm{N} / \mathrm{mm})$ \\
\hline 0.094 & 0.38 & 249.96 \\
0.471 & 1.5 & 249.96 \\
1.033 & 4.1 & 249.99 \\
2.047 & 8.2 & 250.06 \\
\hline \hline
\end{tabular}




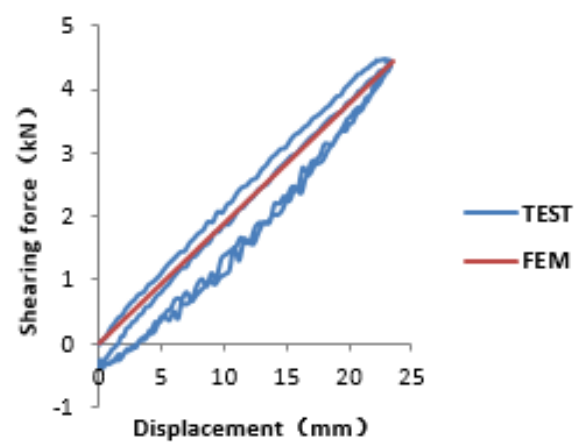

Fig. 6. Shearing force-displacement curves of SLEB.

\section{SiMULATION OF SLIPPING OF SLEB}

In FEM model, the upper surface of the SLEB is fixed on the connecting plate, and slipping is allowed to occur at the lower surface. The deformation of the bearing is shown in Fig. 7.
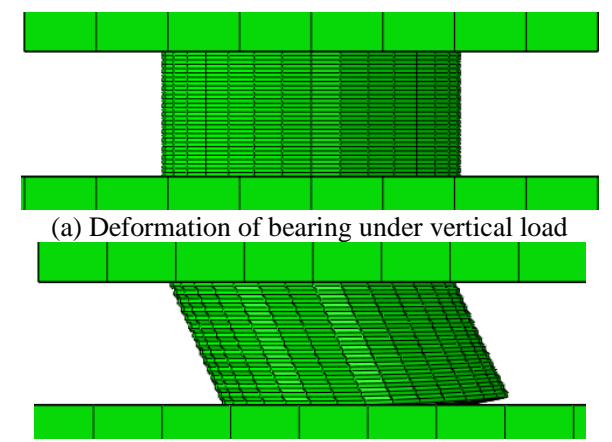

(b) Deformation of bearing under vertical load and horizontal load Fig. 7. Deformation of SLEB under different loads.

The friction coefficient in penalty friction model is 0.51 , which is the value when the vertical load is $1.0 \mathrm{t}$. The loading is at a speed of $0.5 \mathrm{~mm} / \mathrm{s}$ and the max displacement is $80 \mathrm{~mm}$. The residual force in bearing is also considered. The test and FEM results of horizontal force-displacement curves are shown in Fig. 8.

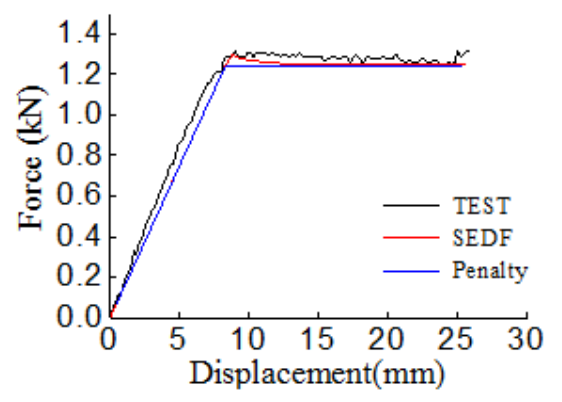

(a) vertical load at $0.2 \mathrm{t}$

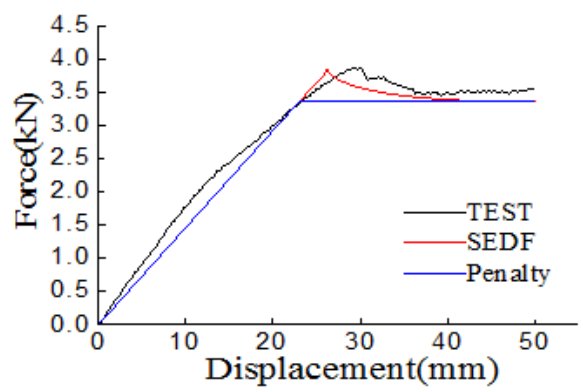

(b) vertical load at $0.6 \mathrm{t}$

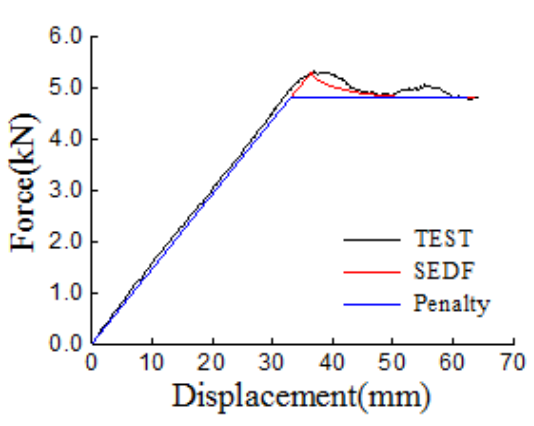

(c) vertical load at $1.0 \mathrm{t}$

Fig. 8. Comparison of Test and FEM results under different vertical loads

It shows that results of two friction models are in good accordance with the test results in Fig. 8. The SEDF model is closer to the test results. What causes the differences between the two friction models is as follows: 1) at the beginning of the bearing sliding, relative velocity between SLEB and concrete plate increased which decreased the friction coefficient; 2) at the maximum loading displacement, loading velocity decreased which increased the friction coefficient.

\section{PARAMETERS ANALYSIS}

Two friction model can be used to simulate the process of bearing slipping. The penalty friction model is only defined by a constant friction coefficient, which treat maximum static friction force as the sliding friction and cannot simulated the discontinuous friction slipping. SEDF model is a better model by contrast. The differences of results of two friction model are shown mainly as follows:

\section{A. The Initial Slipping Point}

Initial slipping point is a symbol of bearing capacity. The displacement value of the initial slip points of bearing test and finite element simulation is given in Table II.

TABLE II: INITIAL SLIPPING DISPLACEMENT OF SLEB

\begin{tabular}{cccc}
\hline \hline Vertical & \multicolumn{3}{c}{ Displacement $(\mathrm{mm})$} \\
\cline { 2 - 4 } Load $(\mathrm{t})$ & TEST & SEDF & Penalty \\
\hline 0.2 & 9.0 & 8.8 & 8.3 \\
0.6 & 23.5 & 24.3 & 21.2 \\
1.0 & 36.9 & 36.4 & 34.7 \\
\hline \hline
\end{tabular}

\section{B. Equivalent Shearing Stiffness of SLEB}

When slipping occurs, equivalent stiffness is commonly used to describe the performance of bearings. Under $0.6 \mathrm{t}$ of weight in two models, the results of FEM and test are shown in Fig. 9. SEDF model is in better accordance with the test results,

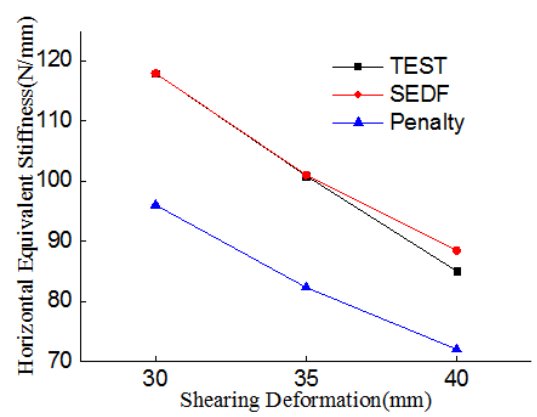

Fig. 9. Comparison of horizontal equivalent stiffness. 
As shown in Fig. 9 when shear deformation is at $30 \mathrm{~mm}$, SEDF model results is the same as the test results, whereas penalty friction model result is $21.9 \mathrm{~N} / \mathrm{mm}$; At the shearing deformation of $35 \mathrm{~mm}$, SEDF model test value and the result is almost the same, penalty friction model result is 18.77 $\mathrm{N} / \mathrm{mm}$; At the shearing deformation of $40 \mathrm{~mm}$, there is a little difference between SEDF model results and the test results. There is a big difference between the results of penalty friction model the test results.

\section{Equivalent Viscous Damping Ratio}

The equivalent viscous damping ratio is one of the most important performance indicators, which reflects the energy consumption capacity of structure under seismic action. Hysteresis curves under 0.6 t are shown in Fig. 10.

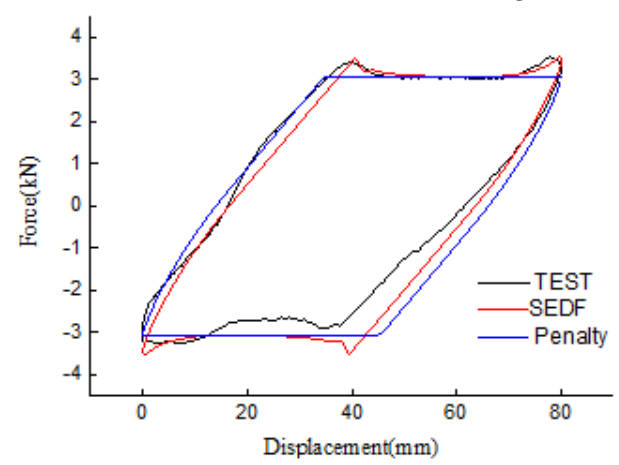

Fig. 10. Comparison of hysteresis curves.

Further FEM simulation is carried out to analysis the under various load cases. As shown in Fig. 11, the equivalent damping ratio of SLEB increases by the shearing deformation for both SEDF model and penalty friction models. The equivalent damping ratio of SLEB increases with the decreasing of loading speed. The equivalent damping ratio of SLEB modeled by penalty friction model is the smallest.

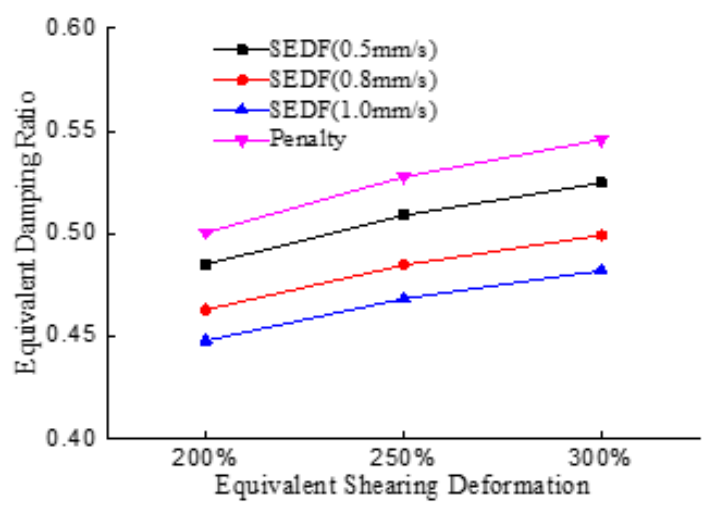

Fig. 11. Equivalent damping ratio at different velocities.

From the above analysis, the two friction models can be used to simulate bearing friction slipping phenomenon. The calculation process of penalty friction model is simpler than the SEDF models, but has a poor accuracy. SEDF model may lead to a better results.

\section{CONCLUSION}

1) Friction coefficient of SLEB is related to the vertical pressure and loading speed, with the increase of the vertical stress and the increase of loading rate.
2) The test results show that the friction coefficient of SLEB and concrete plate is between 0.5-0.6, which is much greater than the recommend one 0.15 , in Guidelines for Seismic Design of Highway Bridges (JTG/T B02-01-2008, a China bridge design code).

3) In general, when the horizontal load is more than the shearing force of $100 \%$ shear deformation of SLEB, slipping will happen, which can be used as a criteria to determine whether SLEB slips or not.

4) The equivalent damping ratio of SLEB decreases with the increase of loading speed, as well as the equivalent shear deformation.

5) A fine FEM model of SLEB is established, incorporating material, geometric nonlinearities, and frictional contact between bearing surfaces and plates. SEDF model is accurate enough to simulate the SLEB friction slipping for bridge seismic design and analysis.

\section{ACKNOWLEDGMENT}

The writers are grateful for the support from the National Natural Science Foundation of China (Grant No.51178220 and 51108234), the Transportation Science and Technology project (2013Y12) and the Science and technology support program (BE2014716), Jiangsu, China.

\section{REFERENCES}

[1] R. Z. Wang, S. K. Chen, and K. Y. Liu, "Analytical simulations of the steel-laminated elastomeric bridge bearing," Journal of Mechanics, vol. 30, no. 04, pp. 373-382, Aug 2014

[2] O. N. Hamzeh, J. L. Tassoulas, and E. B. Becker, "Behavior of elastomeric bridge bearings: computational results," Journal of Bridge Engineering, vol. 3, no. 3, pp. 140-146, 1998

[3] M. Imbimbo and A. D. F. E. Luca, "Stress analysis of rubber bearings under axial loads," Computers and Structures, vol. 68, no. 1, pp 31-39, 1998.

[4] H. H. Nguyen and J. L. Tassoulas, "Directional effects of shear combined with compression on bridge elastomeric bearings," Journal of Bridge Engineering, vol. 15, no. 1, pp. 73-80, 2009.

[5] N. Hinrichs, M. Oestreich, and K. Popp, "On the modelling of friction oscillators," Journal of sound and Vibration, vol. 216, no. 3, pp. 435-459, 1998.

[6] Z. J. Li, G. Fei, and X. U. Xu, "Finite element simulation and experiment study of property for elastomeric pad bearing," Journal of Southeast University (Natural Science Edition), vol. 43, no. 6, pp. 1299-1304, 2013.

[7] W. Gang, W. Kehai, L. Chong, and Y. G. Hui, "Parametric finite element investigation of laminated rubber bearings with friction slipping," China Civil Engineering Journal, vol. S1, pp. 108-112, 2014.(in Chinese)

[8] S. S. Joshua et al., "Shear and friction response of nonseismic laminated elastomeric bridge bearings subject to seismic demands," Journal of Bridge Engineering, vol. 18, no. 7, pp. 612-623, 2012.

[9] K. M. James and D. Konstantinidis, Mechanics of Rubber Bearings for Seismic and Vibration Isolation, John Wiley \& Sons, 2011

[10] R. A. Mooney, "Theory of large elastic deformation," Application of Physics, vol. 11, pp. 582-592, 1940

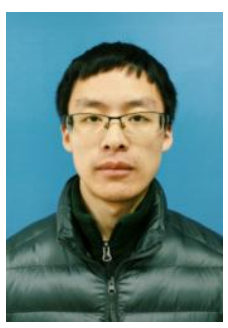

Weiguo Huang was born in Jiangsu, China, in June 1992. He received his bachelor degree from the Nanjing Tech University in Nanjing of China in 2014 His main research fields are bridge seismic design and vibration control, bridge stochastic vibration

He pursues a degree of $\mathrm{PhD}$ at Nanjing Tech University right now. 


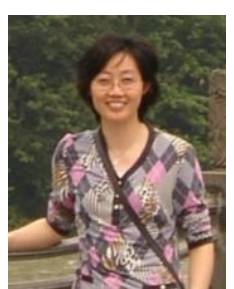

Xiuli Xu was born in Jiangsu, China, in April 1963 She received $\mathrm{PhD}$ from the Southeast University 2009 in Nanjing of China. Her main research fields are bridge seismic and seismic control, bridge life cycle information technology (BrIM), steel bridge standardization design and construction technology.

She has been teaching at Nanjing Tech University since 1985. She is currently a professor in the department of bridge engineering at college of Civil Engineering. She had undertaken a number of research projects, such as the key basic research and development program of China, the National Natural Science Foundation of China, the Transportation Science and Technology project and the Science and technology support program. Her main papers are shown as follow: " X. Xu, X. Xu, W. Liu et al., "A new formula of impact stiffness in linear viscoelastic model for pounding simulation," Shock and Virbration, 2016, vol. 4, pp. 1-7, 2016; "X. Xu, W. Liu, R. Wang et al., "Full-bridge aero-elastic model wind-tunnel tests for long-span cable stayed bridge with viscous dampers," in Porc. Transportation Research Board 90th Annual Meeting, 2011; "X. Xu, W. Liu, Z. Wang et al., "A matter of restraint: Damping the Hangzhou bay bridge," Bridge Design \& Engineering, 2005.

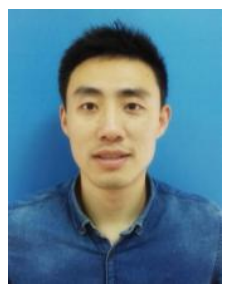

Kairui Wang was born in Jiangsu, China, in October 1986. He received Master Degree from the Nanjing Tech University 2013 in Nanjing of China. His main research fields are bridge seismic and seismic control, bridge life cycle information technology (BrIM).

$\mathrm{He}$ pursues a degree of $\mathrm{PhD}$ at Nanjing Tech University right now. His main papers are shown as follow: "K. Wang, X. Xu, X. Li, Z. Li, W. Liu," Shake-Table Study of a continuous girder bridge with "Lead rubber bearing under high intensity earthquake," Bridge Construction, vol. 46, no. 5, pp. 59-64, 2016; Z. Li, K. Wang, X. Xu, S. Wang, X, Li, K. Wang, "Seismic response analysis and optimization design of extra wide bridge," Earthquake Engineering \& Engineering Dynamic, vol. 34, no. 2, pp. 120-128 s, 2014; Z. Li, F. Ge, X. Xu, K. Wang, "Finite element simulation and experimental study of property for elastomeric pad bearing," Journal of Southeast University, vol. 43, no. 6, pp. 1299-1304, 2013.

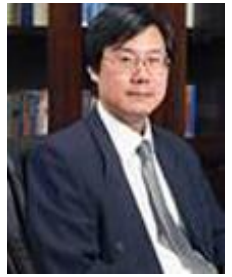

Weiqing Liu was born in Jiangsu, China, in March 1964. He received $\mathrm{PhD}$ from the Southeast University 1995 in Nanjing of China. His main research fields are structural damping control, composite structure, modern wood structure, concrete structure.

He has been teaching at Nanjing Tech University since 1988 . He is currently a professor in the department of bridge engineering at college of Civil Engineering and the vice President of Nanjing Tech University. He had undertaken a number of research projects, such as the key basic research and development program of China, the key projects of National Natural Science Foundation of China, the National Natural Science Foundation of China. His main papers are shown as follow: L. Wang, W. Liu, Y. Fang et al., "Axial crush behavior and energy absorption capability of foam-filled GFRP tubes manufactured through vacuum assisted resin infusion process," Thin-Walled Structures, vol. 98, pp. 263-273, 2016; W Liu, F. Zhang, L. Wang et al., "Flexural performance of sandwich beams with lattice ribs and a functionally multilayered foam core," Composite Structures, vol. 152, pp. 704-711, 2016; J. Wang, W. Liu, L. Wang et al., "Estimation of main cable tension force of suspension bridges based on ambient vibration frequency measurements," Structural Engineering and Mechanics, vol. 56, no. 6, pp. 939-957, 2015.

Prof. Liu is the executive member of Anti-Seismic System International Society (ASSISi), the vice chairman of the Chinese Modern Timber Architecture Technology Industry Association, the director of Chinese Architecture Society and Mechanics Society. 